\title{
CULTURAL ADAPTATION AND VALIDATION OF THE "DIABETES QUALITY OF LIFE FOR YOUTHS" MEASURE OF INGERSOLL AND MARRERO INTO BRAZILIAN CULTURE
}

\author{
Tatiana de Sá Novato ${ }^{1}$ \\ Sonia Aurora Alves Grossi \\ Miako Kimura ${ }^{3}$
}

Novato TS, Grossi SAA, Kimura M. Cultural adaptation and validation of the "Diabetes Quality of Life for Youths" measure of Ingersoll and Marrero into Brazilian culture. Rev Latino-am Enfermagem 2008 março-abril; 16(2):224-30.

The aim of this study was to adapt the "Diabetes Quality of Life for Youths (DQOLY)" measure into Brazilian culture and to analyze its psychometric properties. The cross-cultural adaptation included the phases of translation, backtranslation, committee review, and pretesting. The adapted instrument was applied to 124 type 1 diabetes mellitus'adolescents. The reliability results showed adequate Cronbach's alpha coefficients (0.8695 for Satisfaction domain, 0.8658 for Impact, 0.8387 for Worries and 0.9333 for total), with the exclusion of 3 inconsistent items. The testretests showed no significant difference between two instrument's applications in different periods $(p>0.05)$. The validity was demonstrated by the strategies: content, convergent, factorial and discriminant. All subscales showed positive correlations between itselves $(p<0.001)$ and with the adolescents' self-perception of their health status $(p<0.001)$. The present study suggests that this version of the DQOLY is a reliable and valid measure for its use in Brazil.

DESCRIPTORS: diabetes mellitus, type 1; quality of life; adolescent; validation studies

\section{ADAPTACIÓN CULTURAL Y VALIDACIÓN PARA LA CULTURA BRASILEÑA DEL INSTRUMENTO "DIABETES QUALITY OF LIFE FOR YOUTHS" DE INGERSOLL Y MARRERO}

El objetivo de este estudio fue realizar la adaptación para la cultura brasileña del instrumento "Diabetes Quality of Life for Youths (DQOLY)" y analizar su capacidad psicométrica. La adaptación cultural constó de: traducción, retrotraducción, revisión por el comité y el pre-test. El instrumento adaptado fue aplicado en 124 adolescentes con diabetes mellitus tipo 1. La confiabilidad tuvo un alpha de Cronbach adecuado para el dominio Satisfacción (0,8695), de 0,8658 para el Impacto, de 0,8387 para las Preocupaciones y de 0,9333 para todo el instrumento, siendo excluidos 3 ítems inconsistentes. La prueba/ reprueba demostró no existir diferencia significativa entre las dos aplicaciones del instrumento durante periodos diferentes $(p>0,05)$. La validación fue demostrada por las estrategias: contenido, convergencia, factorial y discriminación. Todas las sub-escalas tuvieron correlaciones positivas entre sí $(p<0,001)$ y con la auto-percepción del estado de salud $(p<0,001)$. El presente estudio concluye que la versión del DQOLY es una forma de medición confiable y válida para ser usada en el Brasil.

DESCRIPTORES: diabetes mellitus tipo 1; calidad de vida; adolescente; estudios de validación

\section{ADAPTAÇÃO CULTURAL E VALIDAÇÃO DA MEDIDA "DIABETES QUALITY OF LIFE FOR YOUTHS" DE INGERSOLL E MARRERO PARA A CULTURA BRASILEIRA}

O objetivo deste estudo foi realizar a adaptação da medida "Diabetes Quality of Life for Youths (DQOLY)" para a cultura brasileira e analisar suas propriedades psicométricas. A adaptação cultural incluiu as fases: tradução, retrotradução, revisão por comitê e pré-teste. O instrumento adaptado foi aplicado a 124 adolescentes com diabetes mellitus tipo 1. Os resultados de confiabilidade indicaram alphas de Cronbach adequados (0,8695 para o domínio Satisfação, 0,8658 para o Impacto, 0,8387 para Preocupações e 0,9333 para o total), com a exclusão de 3 itens inconsistentes. 0 teste-reteste demonstrou não haver diferença significativa entre duas aplicações do instrumento em períodos diferentes $(p>0,05)$. A validação foi demonstrada pelas estratégias: conteúdo, convergente, fatorial e discriminante. Todas as sub-escalas indicaram correlações positivas entre si $(p<0,001)$ e com a auto-percepção do estado de saúde $(p<0,001)$. O presente estudo sugere que a versão do DQOLY é uma medida confiável e válida para o uso no Brasil.

DESCRITORES: diabetes mellitus tipo 1; qualidade de vida; adolescente; estudos de validação

${ }^{1}$ PhD student, RN at the University Hospital, e-mail: tatiananovato@hotmail.com; ${ }^{2}$ Assistant Professor at School of Nursing, e-mail: sogrossi@usp.br; Faculty, e-mail: mikimura@usp.br. University of São Paulo, School Nursing, Brazil 


\section{INTRODUCTION}

$\boldsymbol{T}_{\text {ype }} 1$ diabetes mellitus(DM) is one of the most common chronic diseases in infancy and adolescence ${ }^{(1)}$. Clinical, biochemical and epidemiological evidence confirms that the maintenance of glycemic parameters at levels close to normal reduces the incidence and severity of longterm complications of diabetes ${ }^{(2)}$. This strict glycemic control requires special self-care behaviors which are not easily incorporated, especially during adolescence.

The difficulty if achieving these self care behaviors and maintaining the adequate metabolic control can be attributed to the changes in socioemotional, cognitive and physiological aspects during adolescence ${ }^{(3)}$. Therefore, other aspects in addition to metabolic control started to serve as parameters of the success of treatment, considering that living with the disease and requirements related to glycemic control, insulin therapy, diet and physical activity have a strong impact not only on the physiological but also on the psychosocial functioning of the adolescent Assessment of the quality of life (QOL) has been considered an important parameter in the understanding of this impact ${ }^{(4)}$ since it provides data for the development of more effective interventions by evaluating the repercussions of the chronic condition from the perspective of the individual. It is believed that contemplating individual perceptions of QOL facilitates treatment compliance ${ }^{(5)}$.

The Diabetes Quality of Life(DQOL) measure was the pioneering specific instrument to assess quality of life an it consists of the following four subscales: satisfaction, disease impact on daily life, disease-related worries, and vocational worries ${ }^{(6)}$. In order to determine its specificity within the context of life of the young diabetic, this instrument was adapted ${ }^{(5)}$ by including questions related to the routine of youngsters such as school and worries about the future, and called it the Diabetes Quality of Life for Youths(DQOLY) measure.

A literature search of the Medline, Lilacs and Embase databases did not identify any specific instrument constructed or adapted for the Brazilian culture able to evaluate the QOL of young diabetic individuals. Thus, the objectives of the present study were to culturally adapt and to validate the DQOLY measure for the Brazilian culture and to determine the relationship between its scores and sociodemographic, clinical variables and self perception of health status.

\section{RESEARCH DESIGN AND METHODS}

The study was conducted in two phases: cultural adaptation (phase 1 ) and analysis of reliability and validity (phase 2).

The DQOLY is a specific self-report measure designed to assess the quality of life of type one diabetes youths. The questionnaire consists of 51 items divided into Satisfaction, Impact and Worries subscales with 17, 23 and 11 items, respectively. Likert-type questions with five response options are used, which range from very satisfied to very unsatisfied in the Satisfaction subscale and from never to always in the Impact and Worries subscales. The lowest score corresponds to the "best $\mathrm{QOL}^{\prime}$, except for one question in the Impact subscale which is inverted. In addition, a question, related to the health perception compared to other adolescents, was added to the instrument ${ }^{(5)}$.

Phase 1: Cultural Adaptation

Permission to translate the DQOLY into Brazilian Portuguese was obtained from one

of the DQOLY's authors, Dr Gary Ingersoll. This phase was carried out according to methods recommended in the literature ${ }^{(7)}$.

The translation of the instrument into Brazilian Portuguese language was done independently by two Brazilians translators, who knew the study's objectives. The two Portuguese versions generated one version after authors consensus (DQOLY 1) and then, it was submitted to back-translation, done by two others translators, residents in USA and England They did not have contact with the original instrument, generating DQOLY 2. Subsequently, it that was submitted to a committee of experts, composed by 6 multidisciplinary diabetes specialists, with English language domain. They compared each item of the original instrument and the translated version in relation to semantic/idiomatic equivalences in order to assure the correct translation.

After this process, DQOLY 3 was generated and submitted to another committee composed by 5 specialists in instrument's adaptation. Only DQOLY 3 was available and they had to assure the cultural equivalence, which is related to the context and the life experiences in Brazilian population, and conceptual equivalence, which is the verification of the original instrument concept maintenance at the translated version. It was considerate 
consistent items with $80 \%$ of concordance in all equivalences analysis. Another version was generated after these analyses: DQOLY 4 and it was applied to 12 adolescents who answered the instrument and suggested modifications in order to improve the comprehension of some items. The version DQOLY 5 was submitted to the reliability and validity analyses and from now, we will call it DQOLY Brazilian version.

Phase 2: Analysis of Reliability and Validity

The instrument was applied between November 2003 and May 2004 at the Diabetes outpatient clinic of the Children's Institute, Diabetes outpatient clinic of the University Hospital, and the Diabetes Control League of the Discipline of Endocrinology, São Paulo University School of Medicine, which are referral centers in the treatment of DM.

The Brazilian version of the instrument was applied to adolescents with type 1 DM and the results provided data for the analysis of its reliability and validity. The adolescents responded to the questions of the instrument while waiting for their medical visit in the waiting room of the reported services. The instrument was self-administered.

The sample was composed by 124 patients (65 female, 59 male). The average age was 14.74( \pm 2.11) and age ranged from 12 to 18 years old. The disease duration ranged from 1 to 16 years (average value $6.2 \pm 3.93$ ).

Reliability represents the reproducibility of the instrument's results in different conditions ${ }^{(8)}$. Reliability of the adapted DQOLY was evaluated by test-retest analysis. Fourteen patients included in the sample were retested by a second application of the instrument within a period of 15 to 20 days after the first application. Reliability was also tested by the analysis of total internal consistency and the consistency of each subscale using Cronbach's alpha coefficient. Criteria used for inconsistent items exclusion were lower correlation $(<0,2)$ or negative correlations, except for inverted items.

Validity is the instrument property to measure what it proposes ${ }^{(8)}$. Based on the data obtained in the evaluation of conceptual equivalence, content validity was determined using the content validity index(CVI) ${ }^{(9)}$ calculated for each pair of experts as follows:

$C V I=\frac{\text { No. Of items considered to be equivalent by two experts }}{\text { Total number of items of the scale }}$
A CVI higher than 0.8 is desired, which indicates adequate agreement between experts ${ }^{(9)}$.

Construct validity was determined based on convergent validity. The raised hypothesis was that self-esteem variables and QOL are positively correlated ${ }^{(10)}$. This validity was determined by correlating the scores obtained for the DQOLY Brazilian version and for Rosenberg's self-esteem scale. The latter has been validated for the Brazilian population (11). This scale was self-administered. Construct validity was also determined by factorial analysis despite the small size of the sample.

Discriminant validity was analyzed to determine whether the instrument is able to discriminate between groups by comparing the scores obtained with the QOL measure between 2 groups of patients: with the poorest $(\mathrm{HbA} 1 \mathrm{c} \geq 7)$ and best glycemic control (HbA1c $\leq 7$ ). Glycosylated hemoglobin (HbA1c) was chosen as a metabolic control parameter to test discriminant validity because professionals tend to associate good metabolic control of diabetes with $\mathrm{QOL}$, as reported in several studies ${ }^{(12-13)}$. The total and subscale scores were compared.

\section{Statistical Procedures}

The data were tabulated in an Excel databank and processed with the help of Statistical Package for Social Sciences, version 10.0. A level of significance of 0.05 was adopted. The following tests were used: paired t-test for test-retest analysis; Pearson's correlation coefficient for the analysis of construct validity; Student $t$-test for the analysis of discriminant validity and Spearman's correlation coefficient for the determination of correlations between the subscales of the DQOLY measure and self-perception of health status.

The study was approved by the Ethics Committees of the Nursing School, University of São Paulo (process No. 282/2003). Anonymity and the possibility to withdraw from the study at any time were guaranteed to the participants who signed an informed consent form.

\section{RESULTS}

Phase 1: Cultural adaptation

In this phase, alterations were introduced in the items of the instrument with the suggestions of 
the patients, researchers and experts in order to improve it comprehensiveness and in general, it did not involve contents of any item. Special attention was given to the item related to drive a car. In Brazil, by law, people can not drive before 18 years old. The author of the original instrument suggested maintaining this item until the reliability phase in order to analyze how this item is related with the others of the scale. The results are decrypted below.

Phase 2: Analysis of Psychometric Properties

\section{Reliability}

Internal consistency data of the adapted instrument using Cronbach's alpha coefficient scored 0.8695 for Satisfaction domain, 0.8658 for Impact and 0.8387 for Worries. In the Satisfaction and Worries subscales all correlations were significant and positive. In the Impact scale, item 7, "How often do you feel good about yourself", was found to be inverted, and the item "How often does your diabetes prevents you from driving a car" showed the lowest correlation with the subscale (0.1432) and was excluded.

Analysis of total DQOLY Brazilian version, already including the alterations, showed low correlations between two items of the Impact Subscale and the other items of total scale. The inconsistent items, (12 and 21), were "How often do you have to explain to others what it means to have diabetes" (0.1910) and "How often do you think that your parents protect you a lot" (0.1959). The exclusion of these items changed the total scale Cronbach's alpha from 0.9313 to 0.9333 and the coefficient for the Impact subscale from 0.8627 to 0.8658. Analysis of internal consistency permitted the reelaboration of the instrument which now included 17 items in the Satisfaction subscale, 20 in the Impact subscale and 11 in the Worries subscale, for a total of 48 items.

Considering that the response options for each item range from 1 to 5 , scores of 17 to 85 could be obtained for the Satisfaction subscale, of 20 to 100 for the Impact subscale, and of 11 to 55 for the Worries subscale, with the total score ranging from 48 to 240 . Scores were transformed into a $0-100 \%$ scale to facilitate interpretation, with lower scores indicating better QOL.

Another strategy to determine the reliability of the instrument was test-retest analysis. The data were compared, with the instrument already including the alterations described above and the inversion of item 7 in the Impact subscale. The results are shown in Table 1.

Validity

The analysis of conceptual equivalence performed during the cultural adaptation phase by the committee of five experts provided data for the determination of the content validity of the instrument. Analysis of the subscales of the instrument and of total QOL showed a CVI of less than 0.8 for some items indicated by one of the experts, demonstrating that agreement was not unanimous.

In convergent validity, Cronbach's alpha coefficient obtained for the self-esteem scale was 0.8862 , which is considered to be adequate in this analysis. The correlation results are shown in Table 1 , indicating that the lower the score of the QOL measure, the lower the score on self-esteem measure.

Factorial validity was determined by principal component analysis which results in factorial loads that indicate how much each item is associated with each subscale. This approach permitted the grouping of questions according to the correlations between them. Oblique rotation was used, which permits correlation between factors. The three-component solution provided a percent explained variance of only $37.5 \%$, with most items being better located in the first component. The $\mathrm{KMO}$ (Kaiser-Meyer-Olkin measure of sampling adequacy) value was 0.786 , indicating reasonable adequacy of the data upon factorial analysis ${ }^{(14)}$.

The discriminant validity showed significant difference between QOL scores when comparing patients with adequate and inadequate HbA1c levels, except for the Satisfaction subscale $(p=0.082)$ (Table 1 ).

Scores obtained with the application of the Brazilian version of the DQOLY

The mean transformed scores obtained of this sample were 26.59( \pm 14.37$)$ for Satisfaction domain, 31.44( \pm 15.54$)$ for Impact, 32.44( \pm 20.89$)$ for Worries and 29.95 ( \pm 14.37$)$ for DQOLY Brazilian version total. Positives and significant correlations were observed between subscales indicating that the subscales are not independent and between the total and subscale scores and self-perception of health (Table 1 ). 
Table 1 - Scale Statistics of DQOLY brazilian version. São Paulo, 2004

\begin{tabular}{|c|c|c|c|c|c|c|}
\hline & $\begin{array}{l}\text { Test-retest } \\
\text { ( } p \text { value) }\end{array}$ & $\begin{array}{l}\text { Self-esteem } \\
\text { scale }\end{array}$ & Glycosylated hemoglobin - Mean (SD) & $\begin{array}{l}\text { Self-perception } \\
\text { of health }\end{array}$ & Impact & Worries \\
\hline DOQLY-Total & $0.106^{*}$ & $0.588^{* *}$ & $\begin{array}{c}\text { Adequate }(\leq 7)-20.40( \pm 5.46) \\
\text { Inadequate }(\geq 7)-30.98( \pm 14.66)^{\star \star *}\end{array}$ & $0.507^{\star \star \star \star \star *}$ & - & - \\
\hline Satisfaction & $0.153^{*}$ & $0.539^{\star * *}$ & $\begin{array}{l}\text { Adequate }(\leq 7)-19.61( \pm 10.00) \\
\text { Inadequate }(\geq 7)-27.34( \pm 14.90)\end{array}$ & $0.487^{* \star \star \star * *}$ & $0.644^{\star \star \star \star *}$ & $0.465^{\star \star \star \star \star \star}$ \\
\hline Impact & $0.086^{*}$ & $0.559^{* *}$ & $\begin{array}{c}\text { Adequate }(\leq 7)-18.65( \pm 6.88) \\
\text { Inadequate }(\geq 7)-32.81( \pm 15.60)^{\star * *}\end{array}$ & $0.472^{* \star \star \star *}$ & - & $0.713^{\star \star \star \star \star}$ \\
\hline Worries & $0.536^{*}$ & $0.424^{\star *}$ & $\begin{array}{c}\text { Adequate }(\leq 7)-24.81( \pm 7.78) \\
\text { Inadequate }(\geq 7)-33.26( \pm 21.70)^{\star \star \star \star}\end{array}$ & $0.399^{\star \star \star \star * *}$ & - & - \\
\hline
\end{tabular}

* Mean scores between the first and second application of the DQOLY Brazilian Version- Paired $t$-test

$* * \mathrm{p}<0.001$ - Pearson's correlation between DOQLY Brazilian Version scores and Rosenberg's self-esteem scale.

$* * * \mathrm{p}<0.001-$ Student $t$ - test

$* * * * \mathrm{p}<0.009$ - Student $t$ - test

$* * * * * \mathrm{p}<0.001$ - Spearman's correlation

\section{DISCUSSION}

Over the last few years, the assessment of QOL has become essential in the health area and various instruments for its evaluation have been developed, most of them in English ${ }^{(15)}$. No specific measures adapted to the Brazilian culture for the evaluation of QOL in adolescent with DM are available, and therefore in the present study we followed literature recommendations for the cultural adaptation (7) and validation of the DQOLY ${ }^{(8-9)}$.

The adequate Cronbach's alpha coefficients obtained for the Satisfaction and Worries subscales and the lack of negative correlations between items favored the maintenance of its original items. The negative correlation between the Impact subscale's item "How often do you fell good about yourself" and the other items confirmed its inversion and its scores should therefore be interpreted inversely upon subsequent analysis. The weak correlation between the Impact subscale item "How often does your diabetes prevent you from driving a car?" and the other items of this subscale was probably due to the fact that this activity is prohibited by law in Brazil before age 18 and it was therefore excluded. These alterations markedly increased Cronbach's alpha upon analysis of the internal consistency of this subscale (from 0,8289 to 0,8627).

The internal consistency of the total score of the Brazilian version of the DQOLY, including the modifications, was high $(0,9313)$. Exclusion of the 2 items from the Impact subscale, which showed low correlations, increased total Cronbach's alpha subscale and total. Analysis of the internal consistency of the original DQOLY measure resulted in Cronbach's alpha coefficients of $0.85,0.83$ and 0.82 for the Satisfaction, Impact and Worries subscales, respectively ${ }^{(5)}$. In a multicenter study ${ }^{(12)}$, in which the DQOLY was applied to 2101 adolescents with type 1 DM, the Cronbach's alpha coefficients obtained were 0.92 for the Satisfaction subscale, 0.79 for the Impact subscale and 0.84 for the Worries subscale. In another study applying the DQOLY to 69 adolescents, values of 0.88 and 0.82 were reported for the Satisfaction and Worries subscales, respectively ${ }^{(16)}$.

The test-retest indicated the temporal stability of the instrument. Reliability of the Brazilian version of the DQOLY was thus demonstrated.

In analysis of content validity indicated that the agreement between experts was not unanimous, due the discordant responses on one expert. The items were revised and considered to be adequate for the confirmation of the content validity of this instrument.

Determination of the correlation between the QOL measure and the self-esteem scale demonstrated the convergent validity of the Brazilian version of the DQOLY. Positive and significant correlations between QOL and self-esteem measures, as in this study, have been reported in another study ${ }^{(17)}$ when the DQOLY and Offer's Self-Esteem Inventory were applied to 77 adolescents with type 1 DM. Similar results have been demonstrated by the application of a QOL measure(Vécu et Santé Perçue de I'Adolescent - VSPA) to French adolescents using a self-esteem questionnaire(Echelle Toulousaine d'Estime de Soi ETES) for the determination of convergent validity ${ }^{(10)}$. These results indicate that the QOL and self-esteem concepts are related.

Factorial analysis was performed to determine the pertinence of the items in the subscales. The results obtained show that the three-component solution does not correspond to the three subscales of the Brazilian version of the DQOLY. Only eight of the 48 items were located in the second or third 
component. However, their loads in the first component would also be acceptable, characterizing the instrument as one-dimensional. This result is not conclusive considering the lack of similar analyses of the same instrument.

Discriminant validity demonstrated that in adolescents with better metabolic control, diabetes was associated with lower impact, fewer worries, and better $\mathrm{QOL}(\mathrm{p}<0.05)$. The results of the discriminant analysis agree with other studies. A positive correlation between the three subscales and total DQOLY score and adequate HbA1c levels was reported in another study ${ }^{(12)}$. One research demonstrated that adolescents with a lower HbA1c value scored better on the Satisfaction and Worries subscales (13). Another investigation reported a positive correlation between good metabolic control and better Satisfaction and total DQOLY scores, in addition to a positive correlation between the mean $\mathrm{HbA} 1 \mathrm{c}$ collected during the preceding year and all subscales and total DQOLY score ${ }^{(16)}$. Although the results of these studies indicate that better metabolic control is associated with better $\mathrm{QOL}$, other reports did not confirm this relationship $(3,5)$.

The results obtained with the application of the Brazilian version of the DQOLY to the sample studied were similar to those reported in other studies $(3,5)$. Analysis of the Brazilian version of the DQOLY based on the transformed scores demonstrated that all scores obtained for the sample studied were below $50 \%$, indicating good QOL. The mean transformed
DQOLY scores published by one multicentric study ${ }^{(12)}$ were: $25( \pm 18)$ for the Satisfaction subscale, 25( \pm 11 ) for the Impact subscale and $19( \pm 16)$ for the Worries subscale. Comparison of these results with the present study showed higher mean scores for the three subscales(worse QOL), with the greatest differences being observed for the Worries subscale(32.44 \pm 20.89$)$ and the smallest difference for the Satisfaction subscale(26.59 \pm 14.65$)$.

The positive correlation between subscales demonstrates that they are not independent, i.e., the more satisfied the adolescents, the lower the impact of diabetes and the fewer the diabetes-related worries.

The positive correlations observed between the subscales and total score of the Brazilian version of the DQOLY and self-perception of health are in agreement with other studies $(3,5,12,18)$, i.e., the better the adolescents' health perception, the better their QOL.

Analysis of the Brazilian version of the DQOLY demonstrated good psychometric properties in terms of reliability and validity. It is important to emphasize that the validation of an instrument cannot be fully carried out in a single study ${ }^{(8)}$. Thus, further applications of the validated and published Brazilian version of the DQOLY are necessary. Since this is the first Brazilian study employing this instrument, we suggest maintaining items 12 and 21 of the Impact subscale in future applications in order to determine whether their inconsistency compared to the other items observed here will be confirmed.

\section{REFERENCES}

1. Graue M, Wentzel-Larsen T, Hanestad BR, Bastsvik B, Sovik $O$. Measuring self-reported, health-related, quality of life in adolescents with type 1 Diabetes using both generic and disease-specific instruments. Acta Paediatr 2003 October; 92(10): 1190-6.

2. The Diabetes Control and Complications Trial. The effect of intensive treatment of Diabetes on the development and progression of long-term complications in insulin-dependent diabetes Mellitus. N Engl J Med 1993 March-April; 329(14): 977-86.

3. Faro B. The effect of diabetes on adolescents' quality of life. Pediatr Nurs 1999 May-June; 25(3): 247-53.

4. Garratt AM, Schmidt L, Fitzpatrick R. Patient-assessed health outcome measures for diabetes: a structured review. Diabet Med 2002 January; 19(1): 1-11

5. Ingersoll GM, Marrero D. A modified quality-of-life measure for youths: psychometric properties. Diabetes Educ 1991 March-April; 17(2): 114-8.
6. The Diabetes Control and Complications Trial Research Group. Reliability and validity of a diabetes quality-of-life measure for the diabetes control and complications trial(DCCT). Diabetes Care 1988 October; 11(9): 725-32. 7. Guillemin F, Bombardier C, Beaton D. Cross-cultural adaptation of health-related quality of life measures: literature review and proposed guidelines. J Clin Epidemiol 1993 December; 46: 1417-32.

8. McDowell I, Newell C. Measuring health: a guide to rating scales and questionnaires. 2nd ed. New York: Oxford University Press; 1996.

9. Waltz CF, Strickland OL, Lenz ER. Measurement in nursing research. 2nd ed. Philadelphia: Davis; 1991.

10. Simeoni MC, Auquer $P$, Antoniotti S, Sapin C, San Marco

JL. Validation of a French health-related quality of life instrument for adolescents: the VSP-A. Qual Life Res 2000 March; 9: 393-403.

11. Dini GM. Adaptação cultural, validade e reprodutibilidade da versão brasileira da escala de auto-estima de Rosenberg. [Tese]. São Paulo(SP): Universidade Federal de São Paulo; 2000. 
12. Hvidore Study Group on Childhood Diabetes. Good metabolic control is associated with better quality of life in 2,101 adolescents with type 1 diabetes. Diabetes Care 2001 November; 24(11): 1923-8.

13. Vanelli M, Chiarelli F, Chiari G, Tumini S. Relationship between metabolic control and quality of life in adolescents with type 1 diabetes. Report from two Italian centers for the management of diabetes in childhood. Acta Biomed Ateneo Parmense 2003; 74 Suppl 1:13-7.

14. Pereira JCR. Análise de dados qualitativos. Estratégias metodológicas para ciências da saúde, humanas e sociais. São Paulo: EDUSP; 1999.

15. Dantas RAS, Sawada NO, Malerbo MB. Pesquisas sobre qualidade de vida: revisão da produção científica das universidades públicas do Estado de São Paulo. Rev. Latinoam. Enfermagem 2003 julho-agosto; 11 (4): 532-8.

16. Guttmann-Bauman I, Flaherty B P, Strugger M, McEvoy RC. Metabolic control and quality-of-life self-assessment in adolescents with IDDM. Diabetes Care 1998 June;21(6): 915-8.

17. Ingersoll GM, Marrero DG. Self-esteem and diabetes control in adolescents: a reassessment of a recurring question. Diabetes 1990; 39(1 Suppl):640.

18. Grey M, Boland EA, Yu C, Sullivan-Bolyai S, Tamborlane WV. Personal and family factors associated with quality of life in adolescents with diabetes. Diabetes Care 1998 June; 21(6): 909-14. 